\title{
Emendation of Acetivibrio and Description of Acetivibrio ethanolgignens, a New Species from the Colons of Pigs with Dysentery
}

\author{
I. M. ROBINSON AND A. E. RITCHIE \\ National Animal Disease Center, Agricultural Research, Science and Education Administration, U. S. \\ Department of Agriculture, Ames, Iowa 50010
}

\begin{abstract}
We describe an organism that constituted $20 \%$ or more of the bacterial population in the colons of pigs experimentally infected with Treponema hyodysenteriae. This organism was not found in clinically normal pigs. Because this organism had properties different from those of any previously described taxon, we propose that it be regarded as a new species, Acetivibrio ethanolgignens. The isolates of A. ethanolgignens were obligately anaerobic, gram-negative, nonsporeforming, motile, slightly curved rods with lateral flagella that emanated from the concave sides of the cells and formed fascicles. A. ethanolgignens differs from other species in the genus Acetivibrio principally in its inability to degrade cellulose or ferment cellobiose, its production of ethanol as a major fermentation product, and its possession of multiple flagella. The guanine-plus-cytosine content of its deoxyribonucleic acid is $40 \mathrm{~mol} \%$. The type strain is $77-6$, a culture of which has been deposited in the American Type Culture Collection under the number ATCC 33324. We also emend the description of the genus Acetivibrio to include bacteria with multiple flagella.
\end{abstract}

During studies of the gastrointestinal flora of pigs with clinical dysentery produced by experimental infection with Treponema hyodysenteriae, we isolated a number of obligately anaerobic, motile, gram-negative, rod-shaped bacteria with a unique flagellar arrangement. These organisms were among the predominant bacteria isolated from the colons of two pigs with clinical dysentery. By contrast, similar organisms were not observed as part of the colonic flora of two clinically normal swine from the same herd. These isolates are described below and share a number of features with Acetivibrio cellulolyticus (8), but they differ sufficiently to warrant establishment of a new species.

\section{MATERIALS AND METHODS}

Culture technique and media. The anaerobic methodology and the composition and preparation of CCA rumen fluid roll tube medium and MPY and MPYG media, which are modifications of the peptone yeast media of Holdeman and Moore (2), have been described previously (11). Tests for hemolysis were performed with brain heart infusion agar (bovine blood) as previously described (2).

Isolation and identification. Colonic material was obtained from naturally farrowed cross-bred pigs ( 2 to 3 months old) that had been experimentally infected with $T$. hyodysenteriae. The pigs were part of a study (12) on the pathogenesis of T. hyodysenteriae. The processing of the colon contents and the colon epithelial tissues for culture counts and for isolation of anaerobic bacteria from the gastrointestinal tracts of pigs has been described previously (1).

Isolates were obtained from colonies picked nonselectively from CCA medium in roll tubes.

Cultural and biochemical tests. The methods used for cultural and biochemical characterization of strains have been described previously (11). Susceptibility to antimicrobial agents was tested by the broth disk method of Wilkins and Thiel (13). The guanineplus-cytosine content of the deoxyribonucleic acid of strain 77-6 was determined by the method of Marmur and Doty (5).

Electron microscopy. Cells were harvested from liquid media or slant washings by centrifugation in a swinging bucket rotor for $15 \mathrm{~min}$ at $8,000 \times g$ and then were suspended in water with gentle magnetic stirring. Negative stains were prepared with potassium phosphotungstate (9) or were combined with sodium silicotungstate to enhance the contrast of the subunits of the mantles and flagella of the cells (10). For mensuration of fascicled flagella, some preparations were shadow-cast with germanium.

\section{RESULTS}

We studied the properties of 46 isolates of this bacterium from the colons of pigs with dysentery. These organisms accounted for 18 of 50 $(36 \%)$ and 11 of $50(22 \%)$ of the predominant bacterial strains isolated from the colonic epithelia of the two pigs with clinical swine dysentery. In addition, these organisms represented 17 of $50(34 \%)$ of the predominant bacterial 
strains isolated from the colonic contents of the second pig. By comparison, similar organisms were not observed as part of the colonic flora when we examined 100 isolates from colonic epithelial tissue from each of two clinically normal swine from the same herd.

Morphology. The strains examined consisted of obligately anaerobic, gram-negative, nonsporeforming, motile, slightly curved rods occurring singly, in pairs, and often in short chains. Cells in the early growth phase ( 12 to $24 \mathrm{~h}$ ) were helical curved rods with pointed ends. Filamentous or swollen forms were usually observed in older cultures. Most cells were actively motile in 12- to 24-h-old cultures.

Surface colonies in CCA medium roll tubes were 0.5 to $1.5 \mathrm{~mm}$ in diameter, circular, convex, smooth, translucent, and nonhemolytic.

Ultrastructure of cells. Single cells of representative strains (strains 65-1 and 77-6) were 0.5 to 0.9 by 1.5 to $2.5 \mu \mathrm{m}$ and had 10 to 15 flagella, which were often fascicled (Fig. 1a and 2a). The flagella were arranged linearly on the concave surface and occasionally had prominent basal sacs (Fig. 1b). The flagella were nominally 10 to $12 \mathrm{~nm}$ in diameter and had a wavelength of approximately $3 \mu \mathrm{m}$ and an amplitude of approximately $0.35 \mu \mathrm{m}$. Many cells had a superficial netlike covering or mantle (Fig. $1 \mathrm{~b}$ and $2 \mathrm{a}$ ), whose structural units formed a square array with a spacing of about $10 \mathrm{~nm}$ between rows (Fig. 2b). The following two types of intracellular inclusions were observed regularly: dense, spher-

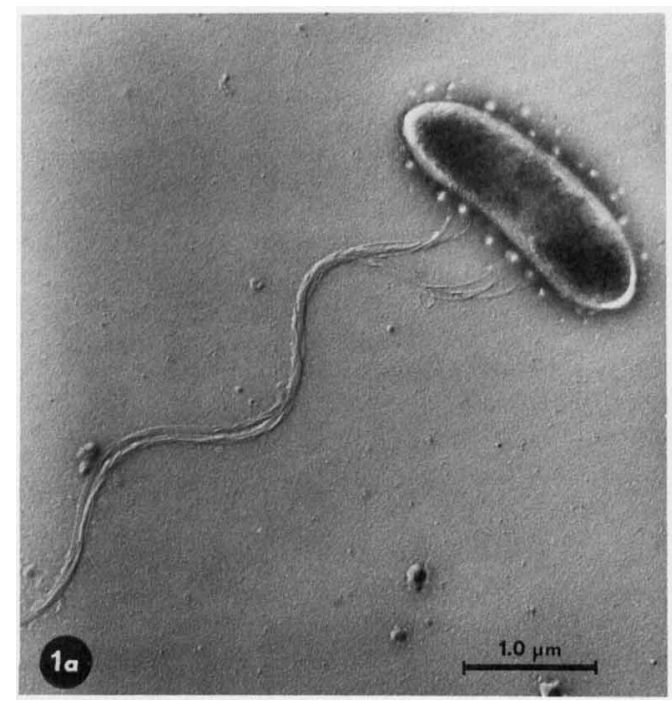

ical to oblate granules 30 to $80 \mathrm{~nm}$ in diameter, which were reminiscent of Heinz bodies, with close clustering of the subunits (Fig. $3 \mathrm{a}$ and b), and rhapidosome-like rodlets 20 by $100 \mathrm{~nm}$ (Fig. 3c).

Cultural and biochemical characteristics. The 46 isolates studied had similar properties. Growth occurred only under anaerobic conditions. No growth occurred on blood agar plates incubated aerobically or if the resazurin in a broth medium became oxidized. There was slight to moderate growth in MPY broth. The growth of cultures in MPY broth containing a fermentable carbohydrate was rapid and heavily turbid; after several days of incubation, cultures cleared, and a thick sediment accumulated. Large amounts of gas were produced rapidly in MPYG broth during growth overnight, and there was an accumulation of foam $(2 \mathrm{~cm}$ above the medium surface) that dissipated within 2 days. Optimal growth was at $37^{\circ} \mathrm{C}$. Slight growth occurred at $45^{\circ} \mathrm{C}$, and no growth occurred at $15^{\circ} \mathrm{C}$. Cultures did not survive heating at $70^{\circ} \mathrm{C}$ for $10 \mathrm{~min}$. Bile was inhibitory for growth. In general, the terminal $\mathrm{pH}$ values of cultures in broth media containing fermentable carbohydrates never dropped below $\mathrm{pH} 6.1$ due to the production of ammonia. However, growth was increased visibly in a medium containing a fermentable carbohydrate, and increased concentrations of ethanol and acetic acid were detected with these substrates. The products of glucose fermentation by the 46 isolates grown on MPYG

Fig. 1. (a) A. ethanolgignens strain 77-6 (germanium shadowed), showing a typical flagellar fascicle. (b) A. ethanolgignens strain 65-1 in phosphotungstic acid-negative stain, showing flagellar basal sacs and the external mantle $(M)$.

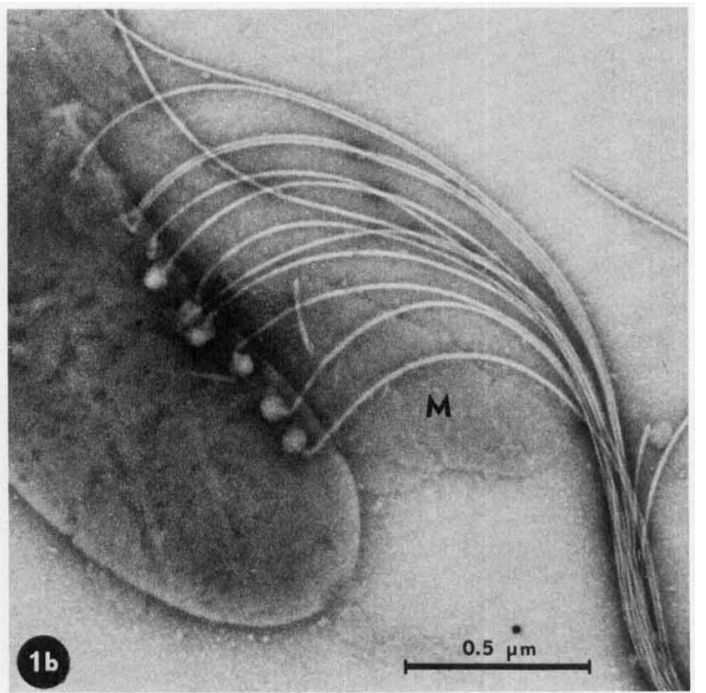



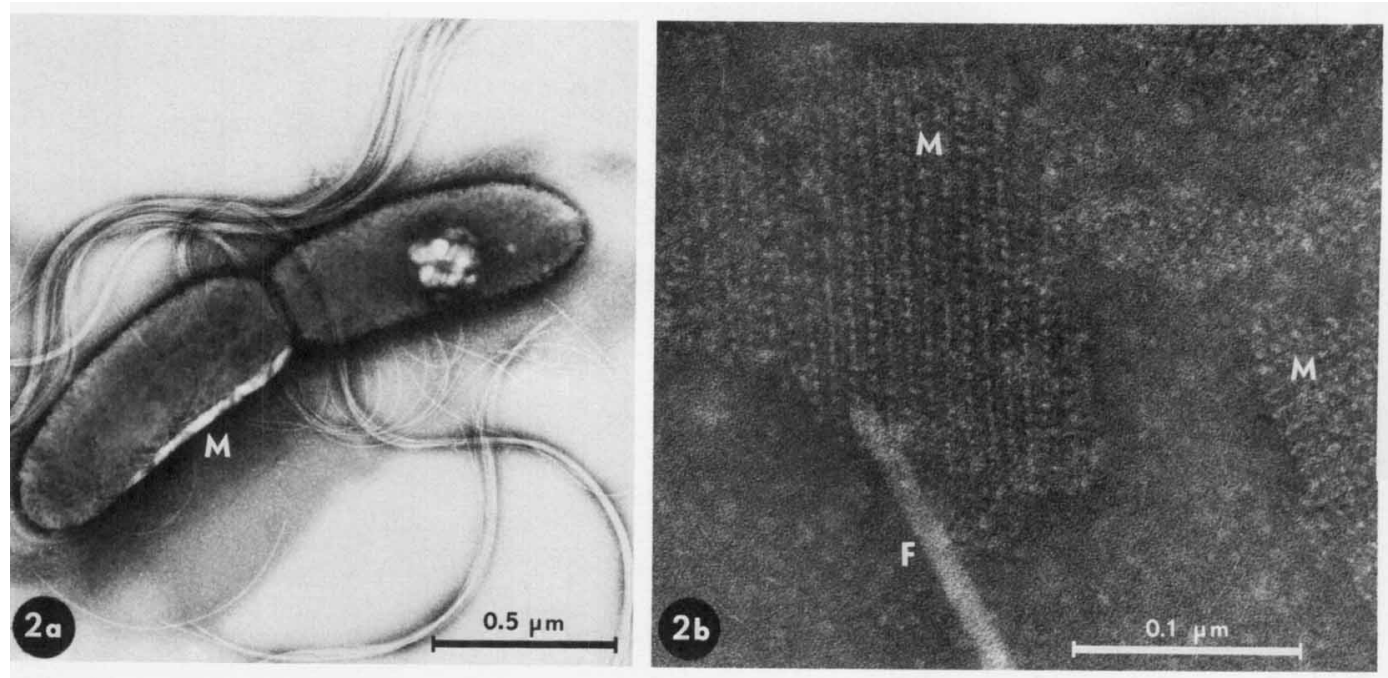

Fig. 2. (a) A. ethanolgignens strain 77-6 dividing cell in phosphotungstic acid-negative stain, showing mantle remnants $(M)$ and fascicled flagella. (b) A. ethanolgignens strain 65-1 fragments of the cell mantle (M) in phosphotungstic acid-negative stain, showing the 10-nm-square array of the mantle subunits. A part of a flagellum $(F)$ is at bottom center.

medium were as follows: acetic acid, $13.57 \pm 3.25$ $\mu \mathrm{mol} / \mathrm{ml}$ (mean \pm standard deviation); and ethanol, $27.01 \pm 5.88 \mu \mathrm{mol} / \mathrm{ml}$.

Table 1 shows the amounts of the products formed by strain 77-6 during growth in MPY broth and in MPY broth containing various substrates. Although there was considerable variability in the concentrations of products between the two trials, in both trials the amounts of ethanol produced from glucose, lactose, maltose, and mannitol were at least three times the amounts produced from the other substrates tested. With these four substrates, assuming the potential to produce $2 \mathrm{~mol}$ of a two-carbon product per mol of hexose, the products accounted for about $70 \%$ of the substrate added to the culture medium.

Table 2 shows other characteristics of strain 77-6 that are representative of the 46 isolates studied. Fructose, galactose, glucose, lactose, maltose, mannitol, mannose, and pyruvate were fermented. Salicin and starch were fermented weakly. Arabinose, cellobiose, esculin, glycerol, inositol, inulin, lactate, raffinose, rhamnose, ribose, sorbitol, sucrose, trehalose, and xylose were not fermented. Ammonia, acetylmethylcarbinol, carbon dioxide, hydrogen, and hydrogen sulfide were produced. Gelatin was hydrolyzed, and nitrate was reduced to nitrite. Milk was not coagulated, and catalase, indole, and urease were not produced. Cellulose was not degraded. When grown in MPYG broth containing antimicrobial agents, strain 77-6 was susceptible to cephalothin $(6 \mu \mathrm{g} / \mathrm{ml})$, chloramphenicol $(5 \mu \mathrm{g} / \mathrm{ml})$, clin- damycin $(2 \mu \mathrm{g} / \mathrm{ml})$, penicillin $(400 \mathrm{U} / \mathrm{ml})$, and vancomycin $(6 \mu \mathrm{g} / \mathrm{ml})$, but resistant to kanamycin $(12 \mu \mathrm{g} / \mathrm{ml})$, neomycin $(12 \mu \mathrm{g} / \mathrm{ml})$, and rifampin $(5 \mu \mathrm{g} / \mathrm{ml})$.

Deoxyribonucleic acid base composition. The guanine-plus-cytosine content of the deoxyribonucleic acid of strain $77-6$ was $40 \mathrm{~mol} \%$.

\section{DISCUSSION}

The 46 isolates included in this study were rather uniform in their characteristics, enough so to warrant their placement in the same taxon. The cellular shape and the unique lateral flagellar arrangement in these isolates resemble the cellular shape and flagellar arrangement reported for Acetivibrio, Pectinatus, Selenomonas, and Syntrophomonas wolfei (6; M. J. McInerney and M. P. Bryant, Abstr. Annu. Meet. Am. Soc. Microbiol. 1980, I62, p. 94) in that the flagella emanate from the concave side of the cells. However, these latter organisms have various other characteristics that differentiate them from the new isolates described here (Table 2). On the basis of several similarities (morphology, acetic acid as a major fermentation product, production of hydrogen and carbon dioxide, and the guanine-plus-cytosine contents of the deoxyribonucleic acids), we determined that our new isolates are more similar to Acetivibrio cellulolyticus (8) than to any other characterized species, but we regard them as belonging to a new species in the genus Acetivibrio.

Acetivibrio ethanolgignens sp. nov. (e. tha. 

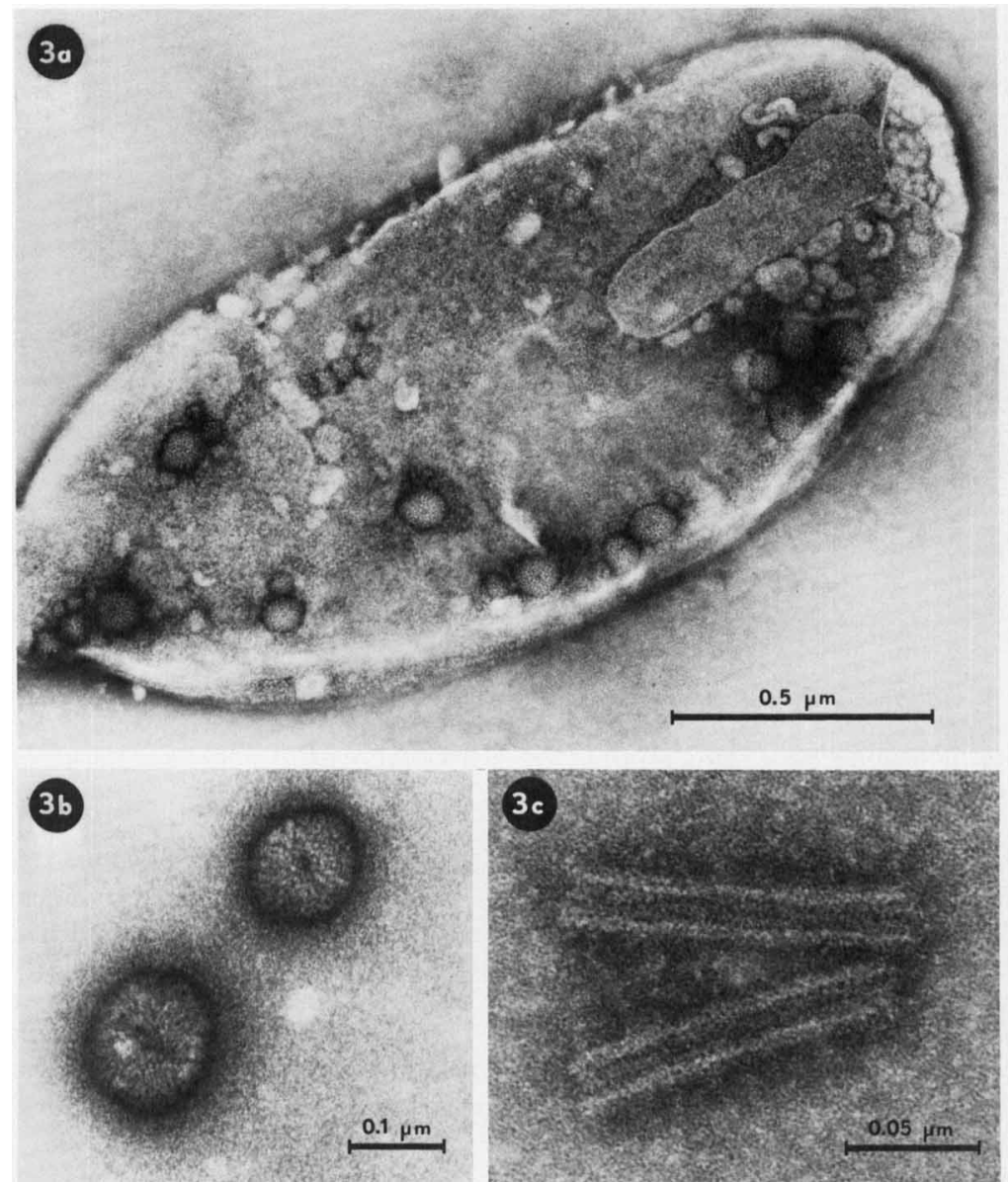

Frg. 3. (a) A. ethanolgignens strain 65-1 in phosphotungstic acid-negative stain, showing a ruptured cell containing cytoplasmic granules. (b) Two cytoplasmic granules in phosphotungstic acid-negative stain, showing characteristic surface detail. From A. ethanolgignens strain 77-6. (c) Two rhapidosome-like rodlets (20 by $100 \mathrm{~nm}$ ) in phosphotungstic acid-negative stain. From A. ethanolgignens strain 77-6.

nol. gig' nens. M. L. noun ethanol ethanol; L. part. adj. gignens giving birth to, producing; $\mathbf{M}$. L. part. adj. ethanolgignens producing ethanol.)

Morphology: gram-negative, nonsporeforming, motile, slightly curved rods, occurring singly, in pairs, and often in short chains. Flagella are arranged linearly on the concave surface of each cell.

Colonies are 0.5 to $1.5 \mathrm{~mm}$ in diameter, circular, convex, smooth, and translucent.

Deoxyribonucleic acid base composition: 40 mol\% guanine plus cytosine.

Temperature for optimal growth: $37^{\circ} \mathrm{C}$.

Physiology: obligately anaerobic. Growth is enhanced by the presence of fermentable carbohydrates. Acetic acid and ethanol are major products of fermentation. 2.
TABLE 1. Fermentation products of $A$. ethanolgignens

\begin{tabular}{lccc}
\hline \multirow{2}{*}{ Carbon source } & \multicolumn{3}{c}{ Amt of the following products $(\mu \mathrm{mol} / \mathrm{ml}):^{a}$} \\
\cline { 2 - 4 } & Formate & Acetic acid & Ethanol \\
\hline MPY broth ${ }^{b}$ & & 9 & 3 \\
Fructose & 6.0 & 5 & 9 \\
Galactose & 2.0 & 9 & 8 \\
Glucose & Trace & 11 & 29 \\
Lactose & Trace & 11 & 30 \\
Maltose & Trace & 13 & 31 \\
Mannitol & Trace & 7 & 31 \\
Mannose & Trace & 8 & 10 \\
Pyruvate & Trace & 57 & 10 \\
Salicin & Trace & 7 & 3 \\
Starch & 2.0 & 8 & 7 \\
\hline
\end{tabular}

${ }^{a}$ Means of two tests with strain 77-6.

${ }^{b}$ Values for products in MPY broth were subtracted from values after growth in MPY containing a fermentable substrate $(5 \mathrm{mg} / \mathrm{ml})$. Cultures were incubated at $37^{\circ} \mathrm{C}$ for 7 days. 
TABLE 2. Characteristics useful in differentiating A. ethanolgignens from A. cellulolyticus, $P$. cerevisiiphilus, and Selenomonas ruminantium (gram-negative, curved, rod-shaped bacteria with lateral flagella) ${ }^{a}$

\begin{tabular}{|c|c|c|c|c|}
\hline Characteristic & A. ethanolgignens & A. cellulolyticus & P. cerevisiiphilus & S. ruminantium \\
\hline Flagella & Fascicle & Subterminal & Comblike & Tufted \\
\hline $\mathrm{H}_{2} \mathrm{~S}$ & $+^{b}$ & - & $\mathrm{NR}(-)$ & \pm \\
\hline Acetylmethylcarbinol & + & - & $\mathrm{NR}(+)$ & - \\
\hline Hydrogen & + & + & NR & $\mathrm{V}$ \\
\hline Carbon dioxide & + & + & NR & + \\
\hline Ammonia & + & - & NR & + \\
\hline Gelatin & + & NR & - & $\mathrm{W}$ \\
\hline Nitrate reduction & + & - & $-(+)$ & \pm \\
\hline Urease & - & - & $\mathrm{NR}(+)$ & \pm \\
\hline \multicolumn{5}{|l|}{ Substrate or reaction: } \\
\hline Adonitol & - & - & + & - \\
\hline Arabinose & - & - & + & + \\
\hline Cellobiose & - & + & + & + \\
\hline Cellulose & - & + & - & - \\
\hline Esculin & - & - & - & + \\
\hline Esculin hydrolysis & - & - & - & + \\
\hline Fructose & + & - & + & + \\
\hline Galactose & + & - & + & + \\
\hline Glucose & + & - & + & + \\
\hline Glycerol & - & - & + & V \\
\hline Lactate & - & - & + & $\mathrm{V}$ \\
\hline Lactose & + & - & - & + \\
\hline Maltose & + & - & + & + \\
\hline Mannose & + & - & + & + \\
\hline Mannitol & + & - & + & + \\
\hline Pyruvate & + & - & NR & + \\
\hline Raffinose & - & - & - & + \\
\hline Rhamnose & - & - & + & - \\
\hline Ribose & - & - & W & + \\
\hline Salicin & + & + & - & + \\
\hline Sorbitol & - & - & $-(+)$ & - \\
\hline Starch & $\mathrm{W}$ & - & - & + \\
\hline Starch hydrolysis & - & - & - & + \\
\hline Sucrose & - & - & _- & + \\
\hline Trehalose & - & - & - & - \\
\hline Xylose & - & - & $\mathrm{W}$ & + \\
\hline \multicolumn{5}{|l|}{ Growth at: } \\
\hline $15^{\circ} \mathrm{C}$ & - & - & + & _- \\
\hline $37^{\circ} \mathrm{C}$ & + & + & + & + \\
\hline $45^{\circ} \mathrm{C}$ & $\mathrm{W}$ & - & - & + \\
\hline \multicolumn{5}{|l|}{ Heat resistant at: } \\
\hline $70^{\circ} \mathrm{C}$ for $10 \mathrm{~min}$ & - & NR & NR & - \\
\hline $80^{\circ} \mathrm{C}$ for $10 \mathrm{~min}$ & - & NR & - & - \\
\hline \multicolumn{5}{|l|}{ Litmus milk: } \\
\hline Curd & - & - & + & + \\
\hline Digestion & - & - & + & - \\
\hline Bile $(20 \%)$ & - & NR & $N R(-)$ & + \\
\hline \multicolumn{5}{|l|}{ Products of fermentation: } \\
\hline Formic acid & w & - & - & _- \\
\hline Acetic acid & + & + & + & + \\
\hline Propionic acid & - & - & + & + \\
\hline Lactic acid & - & - & + & + \\
\hline Succinic acid & - & - & + & - \\
\hline Ethanol & + & W & - & - \\
\hline $\mathrm{H}_{2}$ & + & + & - & + \\
\hline $\mathrm{CO}_{2}$ & \pm & + & - & + \\
\hline
\end{tabular}

${ }^{a}$ In addition, the guanine-plus-cytosine contents of the deoxyribonucleic acids of $A$. ethanolgignens, A. cellulolyticus, $P$. cerevisiiphilus, and S. ruminantium are $40,38,39.8$, and 53 to $61 \mathrm{~mol} \%$, respectively.

${ }^{b}$ Symbols: +, positive reaction; - , negative reaction; \pm , most strains negative, but some strains positive; $V$, variable reaction; $\mathrm{W}$, weak reaction or $\mathrm{pH}$ between 5.5 and $6.0 ; \mathrm{NR}$, results not reported. Symbols in parentheses indicate results not previously reported or different from those previously reported.

Type strain: strain 77-6. This strain has been deposited in the American Type Culture Collection, Rockville, Md., under the number ATCC 33324 .
Source: colons of pigs with dysentery.

The fact that $A$. ethanolgignens was observed consistently in high numbers on the colonic mucosa of pigs with clinical signs of swine dysentery 
but was not detected in similar samples from normal pigs implies that it may have a role in the pathogenesis of swine dysentery. It is known that a colitis similar to swine dysentery can be induced in gnotobiotic pigs by inoculating them with $T$. hyodysenteriae and one or more of several organisms (12). A synergistic relationship exists in that at least one other organism is necessary for T. hyodysenteriae to colonize and express pathogenicity in the colons of gnotobiotic pigs. A. ethanolgignens colonized gnotobiotic pigs in the absence of other contaminating organisms. In gnotobiotic pigs inoculated with A. ethanolgignens and T. hyodysenteriae, clinical and pathological signs of colitis were not observed, although $T$. hyodysenteriae and $A$. ethanolgignens were recovered from the colons of these pigs at necropsy (12). Thus, although $A$. ethanolgignens satisfied the requirement for $T$. hyodysenteriae to colonize the colons of gnotobiotic pigs, pathogenicity was not observed.

The properties of our new isolates of $A$. ethanolgignens resemble those of $A$. cellulolyticus in that both species are gram-negative, anaerobic, nonsporulating, motile, rod-shaped bacteria that produce acetic acid, ethanol, hydrogen, and carbon dioxide as fermentation products. The major differences between the $A$. ethanolgignens isolates described here and $A$. cellulolyticus are that $A$. ethanolgignens does not degrade cellulose or ferment cellobiose, grows without carbohydrate added to MPY medium, produces acetylmethylcarbinol, ammonia, and hydrogen sulfide, and reduces nitrate to nitrite. The flagella of each $A$. ethanolgignens cell form a fascicle that resembles the tuft arrangement on selenomonad cells but differs from the comblike arrangement of Pectinatus flagella or the single subpolar flagellum of $A$. cellulolyticus (8). The deoxyribonucleic acid base composition of $A$. ethanolgignens strain $77-6$ is $40 \mathrm{~mol} \%$ guanine plus cytosine, compared with values of $38 \mathrm{~mol} \%$ for A. cellulolyticus and $39.8 \mathrm{~mol} \%$ for Pectinatus cerevisiiphilus (4). Selenomonads have guanine-plus-cytosine contents of 55 to $60 \mathrm{~mol} \%$ (3). Also, A. ethanolgignens differs from species of Selenomonas and Pectinatus in that it produces ethanol but does not produce propionic or lactic acid. When we examined strain CCB-1022 of $P$. cerevisiiphilus, several properties, including reduction of nitrate and sorbitol fermentation, were different from the properties reported by Lee et al. (4). In addition, the production of acetylmethylcarbinol and urease and the inhibition of growth by bile are properties not previously reported for $P$. cerevisiiphilus.

With the addition of $A$. ethanolgignens to the genus Acetivibrio, the description of the genus will have to be emended to include cells which are motile by a single polar flagellum or by multiple flagella emanating from the concave side of the cells.

\section{ACKNOWLEDGMENTS}

We thank J. L. Johnson, Department of Anaerobic Microbiology, Virginia Polytechnic Institute and State University, Blacksburg, for performing the deoxyribonucleic acid base analysis. We also thank S. Y. Lee, Research and Development, Adolph Coors Co., Golden, Colo., for the culture of P. cerevisiiphilus.

\section{REPRINT REQUESTS}

Address reprint requests to: I. M. Robinson, National Animal Disease Center, Agricultural Research, Science and Education Administration, U.S. Department of Agriculture, P.O. Box 70, Ames, IA 50010.

\section{LITERATURE CITED}

1. Allison, M. J., I. M. Robinson, J. A. Bucklin, and G. D. Booth. 1979. Comparison of bacterial populations of the pig cecum and colon based upon enumeration with specific energy sources. Appl. Environ. Microbiol. 37: $1142-1151$.

2. Holdeman, L. V., and W. E. C. Moore (ed.). 1975 Anaerobe laboratory manual, 3rd ed. Virginia Polytechnic Institute and State University, Blacksburg.

3. Kingsley, V. V., and J. F. M. Hoeniger. 1973. Growth structure, and classification of Selenomonas. Bacteriol. Rev. 37:479-521.

4. Lee, S. Y., M. S. Mabee, and N. O. Jangaard. 1978. Pectinatus, a new genus of the family Bacteroidaceae. Int. J. Syst. Bacteriol. 28:582-594.

5. Marmur, J., and P. Doty. 1962. Determination of the base composition of deoxyribonucleic acid from its thermal denaturation temperature. J. Mol. Biol. 5:109-118.

6. McInerney, M. J., M. P. Bryant, and N. Pfennig. 1979. Anaerobic bacterium that degrades fatty acids in syntrophic association with methanogens. Arch. Microbiol. 122:129-135.

7. Miura, K. 1967. Preparation of bacterial DNA by the phenol-pH-9-RNases method. Methods Enzymol. 12: 543-545.

8. Patel, G. B., A. W. Khan, B. J. Agnew, and J. R. Colvin. 1980. Isolation and characterization of an anaerobic, cellulolytic microorganism, Acetivibrio cellulolyticus gen. nov., sp. nov. Int. J. Syst. Bacteriol. 30: 179-185.

9. Ritchie, A. E., and A. O. Fernelius. 1969. Characterization of bovine viral diarrhea viruses. Arch. Gesamte Virusforsch. 5:369-389.

10. Ritchie, A. E., I. M. Robinson, L. A. Joens, and J. M. Kinyon. 1978. A bacteriophage for Treponema hyodysenteriae. Vet. Rec. 102:34-35.

11. Robinson, I. M., M. J. Allison, and J. A. Bucklin. 1981. Characterization of the cecal bacteria of normal pigs. Appl. Environ. Microbiol. 41:950-955.

12. Whipp, S. C., I. M. Robinson, D. L. Harris, R. D. Glock, P. J. Matthews, and T. J. L. Alexander. 1979. Pathogenic synergism between Treponema hyodysenteriae and other selected anaerobes in gnotobiotic pigs. Infect. Immun. 26:1042-1047.

13. Wilkins, T. D., and T. Thiel. 1973. Modified broth-disk method for testing the antibiotic susceptibility of anaerobic bacteria. Antimicrob. Agents Chemother. 3: $350-356$. 